\title{
Stakeholder participation and the use of web technology for MPA management
}

Markantonatou Vasiliki ${ }^{1 *}$, Manuel Meidinger ${ }^{2,3}$, Marcello Sano ${ }^{2,4}$, Eleni Oikonomou $^{5}$, Giuseppe di Carlo ${ }^{6}$, Marco Palma ${ }^{2}$, Massimo Ponti ${ }^{3}$, Carlo Cerrano $^{1}$

${ }^{1}$ Dipartimento di Scienze della Vita e dell'Ambiente (DiSVA), Università Politecnica delle Marche, via Brecce Bianche, 60131 Ancona, Italy

${ }^{2}$ UBICA s.r.l., Via S. Siro 6/1, 16124 Genova, Italy

${ }^{3}$ Dipartimento di Scienze Biologiche, Geologiche ed Ambientali (BiGeA), Alma Mater Studiorum Università di Bologna, Via S. Alberto 163, 48123 Ravenna, Italy

${ }^{4}$ Griffith Centre for Coastal Management, Griffith University, Gold Coast 4222, Queensland, Australia

${ }^{5}$ Faculty of Art, Design and Architecture, Knights Park, Kinston upon Thames, KT1 2QJ, London, UK

${ }^{6}$ World Wide Fund for Nature (or WWF), Mediterranean Programme Office, Via Po 25/C, 00198 Rome, Italy

Corresponding author: Vasiliki Markantonatou, v.markantonatou@univpm.it 


\title{
Stakeholder participation and the use of web technology for MPA management
}

\author{
Stakeholder participation has received an increased attention as a key process \\ for enhancing open and transparent decision-making in Marine Protected Areas \\ (MPAs) and mitigating conflicts between different interests for the same \\ resources. A wide range of advanced web tools is available nowadays that \\ integrate stakeholder participation by generating new information and allow \\ interaction between actors in MPA management. However, such technologies \\ are frequently used without much consideration of the heterogeneity of \\ stakeholders, the complexity of the decision to be made how particular \\ stakeholder groups understand and are able to relate to these technologies.
}

In order to understand how technology corresponds to the changing needs towards community-based management MPA, we reviewed a range of different participation strategies through examples of web tools from the worldwide arena, starting from simple towards more sophisticated platforms that have been developed in order to better inform decision making, and contribute in a more effective and efficient MPA management. Finally, we suggest a theoretical framework for the development of a community- based web tool with the capacity to incorporate the philosophy of stakeholder participation by generating new and high quality information for a transparent MPA management.

Keywords: Stakeholder participation; Marine Protected Area; resource management; Decision Support Systems; web tools

\section{Stakeholder Participation in Marine Protected Areas: a challenge for managers}

Establishing Marine Protected Areas (MPAs) is one mechanism amongst others that addresses challenges regarding the effective protection and maintenance of ecosystem 
health, the local socio-economic development and the mitigation of conflicting coastal uses (Beck et al., 2009; Ehler and Douvere, 2009; Gopnik, 2008; Halpern et al., 2012; Olsson et al., 2008). Conflicts in MPA management are often hindered by differing interests in the same resources within a fixed space [3,4] De Freitas et al., 2011; Olsen et al., 2013]. Coastal and marine resource managers must bring together stakeholders, and involve them in the management process through multi-disciplinary participatory approaches in order to reach mutual understanding and shared decisions [8-10]; Tempesta \& Otero, 2013; Pomeroy et al., 2004). Stakeholder participation has been characterised as a long and time consuming practice that often slows down decisions [18] and increases the risk of MPA management failure due to distortion of public opinion and strong economic interests [21]. However, many studies argue that local communities are more likely to commit to and comply with long-term conservation strategies when they are involved in MPA decision making processes [23]; [31-36]). The importance of stakeholder involvement has been highlighted in a several international initiatives, such as the Aarhus Convention, the Earth Summit and the European Water Framework Directive.

Stakeholder participation (Table 1) ranges from application of more "extractive” approaches where power is retained in the hands of the administrator and information is limited to passive provision towards stakeholders [11-13], to more interactive or “empowering” approaches like negotiation and consultation where power and responsibility are equally shared to stakeholders [14,15].

[Table 1 here]

The selection of effective communication and information strategies to target the relevant audiences is vital $[40,15,29]$. A spectrum of flexible participatory techniques 
may be necessary to be implemented depending on the objectives set, the level of involvement desired, the target groups, their characteristics and preferences, the past events that have formed the social network, the time constrains and finally the facilitators' experience (Luyet et al., 2012).

Effective participatory process in order to dynamically involve stakeholder groups such as scientists, resource managers, agency staff, stakeholder advisory groups, NGOs, policy advisors and private sector and build constituency for increasing the quality of the MPA decision making process, should support:

(1) Fair and transparent decision-making, where all the diverse stakeholder groups are given the opportunity to participate and share viewpoints (Smith Korfmacher, 2001; Duram and Brown, 1999; Reed, 2008;Webler et al., 2001; Moote et al., 1997; Luyet et al., 2012). This also suggests different dissemination and outreach of information in diverse types in order to reach all preferences and understanding (Masalu, 2008; Dalton, 2005; Creighton, 2005; NOAA, 2007).

(2) Decisions based on complete information, where integration of local and scientific knowledge ensures deep understanding of all critical issues and stakeholder concerns are brought to light and are addressed throughout the process (Luyet et al., 2012). Informing the public includes all kind of activities that promote data availability, accessibility, insurance of data quality and consistency (Carballo- Cardenas et al., 2013), but also collection and validation of information through stakeholders. This also implies that complicated issues should be presented in a way that allows stakeholders from diverse backgrounds to increase their understanding on these issues [6]. 
(3) Active participant involvement and positive participant interaction, where users are linked to eachother and share information more intensely (De Longueville, 2012). Stakeholders not only receive information but also actively contribute in the two-way information input (data, local knowledge, experience and perceptions), or to the development, evaluation and implementation of management plans through knowledge sharing, consultation and dialogue [16,17]; Dalton, 2005; Creighton, 2005; NOAA, 2007). Positive interaction between stakeholders suggests that actors cooperate with each other, possible conflicts that are raised are transformed into positive and common understanding of the issue and viewpoints of different stakes through group problem-solving (Dalton, 2005; Creighton, 2005; NOAA, 2007) generating new options regarding the use of resources $[9,24]$.

(4) Capacity development, in the form of environmental education, awareness and social communication are needed to guarantee behaviour and attitude changes so that the management processes can be sustainable over time $[\underline{15}, \underline{100}]$ [77][79,80] [78]. Social change takes place as people learn from each other through their social networks (Prell et al., 2008).

(5) Efficiency and effectiveness, that will guarantee that the process is successful and sustainable in financial and time limitations (Leach and Pelkey, 2001; Kenney et al., 2000; Luyet et al., 2012).

Web technology with the delivery of spatial information and the use of effective tools in participatory spatial planning has made an important effort in maximising the effectiveness of stakeholder participation in decision-making (De Freitas et al., 2011) through the integration and transformation of local knowledge into maps that are 
easier to understand by all different audiences $[65,66]$. Ecosystem-based approaches like Integrated Coastal Zone Management (ICZM) and Marine Spatial Planning (MSP) have intensively used technology to inform the spatial distribution of the full array of interactions among ecosystem components and human activities (Foley et al., 2010; Katsanevakis et al., 2011] and have brought together multiple stakeholders in order to balance the intensity of existing and potential activities (8-10). Nevertheless, such technologies and related spatial information are frequently used without much consideration of the heterogeneity of stakeholders, the complexity of the decision to be made how particular stakeholder groups understand and are able to relate to these technologies (De Freitas et al., 2011; Luyet et al., 2012). Given the multiple challenges faced in MPA management today [38,39], the current global momentum in establishing MPAs and MPA networks (UNEP-WCMC, 2008; Wood et al., 2008), and the calls for development of user oriented Informational Systems on protected areas (Bertzky and Stoll-Kleemann, 2009; Corrigan and Kershaw, 2008; CarballoCárdenas - 2013), there is an increasing interest for the capacity of web technology in order to enhance interactions between and within user groups, accelerate information exchange and improve the performance of resource management (i.e. Garcia et al. [42]; De Longueville, 2010; Lin et al., 2013, Yang et al., 2010). In order to understand how technology corresponds to the changing needs towards community-based management MPA, we reviewed a range of different participation strategies through examples of web tools from the worldwide arena, starting from simple towards more sophisticated platforms that have been developed in order to better inform decision making, and contribute in a more effective and efficient MPA management. Finally, we suggest a theoretical framework for the development of a community- based web tool with the capacity to incorporate the philosophy of 
stakeholder participation by generating new and high quality information for a transparent MPA decision making process.

\section{Web technology serving stakeholder participation in MPA management}

\subsection{Social media}

Social media (or “Social Web”) have become extremely popular [56] by offering attractive means for interaction and communication [57]. The power of Social Media lies on the ease and speed with which data can be gathered and distributed by a large number of individuals using open software [58]. Numerous social media sites, like Facebook and Twitter, provide a large quantity of information and complexity, easily shared between users and groups through a well-linked network of users $[51,59,60][56]$. For example functions like social bookmarking allow users to save different forms of information (URLs from Web pages, blog articles, images or videos), share them with other users, provide comments and link them with keywords or other web entities by means of "tagging", or comment on the quality of information provided by "rating” and "liking”. These types of multi-sourcing provide access to a huge quantity of resources available through the internet that are indexed, classified and commented upon collectively [53] and increases the possible channels and the speed of two-way information flow within the net. Applications that engage audiences such as real time communication and instant messaging forums, discussion boards and groups, wikis, emails and all other emerging electronic/digital communication applications have the effect of boosting the capacity of these tools to provide successful outcomes through consultation and dialogue processes [51]. 


\subsubsection{Examples of Social media in marine resource management}

Even though the capacity of Social media tools such as Wikipedia, Facebook, Twitter for biological and ecological applications is still relatively underexplored within scientific literature [58], Social media are commonly used in resource management to survey diffusion and delivery of news to the public in a multimedia online format [Sayce et al., 2012] and reach an even broader audience and attract attention to a survey or a website. For example, in the case of California Marine Life Protection Act that aimed at the creation of an MPA network, blogs through Facebook and Twitter were extensively used to address the public perception challenges faced by the Initiative and inform the development of public outreach messaging and materials (Sayce et al, 2013). Open source social media may also facilitate the collection of additional information through targeted surveys or enhance consultation, as in the case of the Social web site established by the European Commission "Your voice in Europe” (http://ec.europa.eu/yourvoice) which is a "single access point” of communication with the stakeholders may express their opinion on EU policies and influence their direction. Communication is based on consultations through straightforward online questionnaires, making it easier both for respondents to participate and for policy makers to analyse the results, and on discussions on the main policy issues and chat on-line to EU's leaders through their personal Facebook and Twitter accounts. The website has been set up in the context of the Interactive Policy Making (IPM) initiative that asks the use of modern technologies, particularly the Internet, to allow both Member State administrations and EU institutions to understand the needs of citizens and enterprises better. Your Voice in Europe enables stakeholders to play an active role in the European policy-making process and is anticipated to assist policy development by allowing more rapid and targeted 
responses to emerging issues and problems, improving the assessment of the impact of policies (or the absence of them) and providing greater accountability to citizens. Launched in 2001, IPM has allowed the successful launch of more than 370 public consultations available on the web portal Your voice in Europe (EC, 2012).

\subsection{Citizen Science platforms in marine resource management}

A key aspect in collaborative geographic applications is the interoperability between geospatial data and tools available on the Internet (i.e. WebGIS) for users to build up their content [54]. Online web mapping services are essential for visualising and inspecting the geospatial data across a map, without the need for specialised technical skills (McClintock, 2013). A variety of free and open source Application Programming Interfaces (APIs) and APPs (applications designed to run on smart phones and tablets) have increased the capacity for freedom of geographic data and support for individual planning using low cost technology [55]. These advantages have made such applications popular for creating coordinated networks of volunteers [69] who undertake research- related tasks such as observation, measurement, or computation [70]. This form of research collaboration or collection and outsourcing of information by non-experts is known as "Citizen science” or “community-based monitoring” $[71,72,58]$. Citizen science addresses the goals of Agenda 21 and the Rio Declaration on Environment and Development (UN 1993), by supporting the notion of community capacity building and involvement in Marine Protected Area (MPA) management globally and by bringing together the public and multi-sector agencies to address natural resource management issues [73],[76] (Irwin et al. 1994; Koss et al., 2009). 
ReefCheck is one of the most successful examples of community-based monitoring worldwide, based on recreational divers that have surveyed over 300 reefs in 31 countries [78]. The worldwide Reef Check Foundation (www.reefcheck.org) is an NGO dedicated to the protection of coral reefs in several places in the world and is supported by national agencies in several countries. Monitoring activities involve volunteers such as recreational divers, students, and citizens. Volunteers are adequately trained to observe, identify and verify the status of coral reefs. Today this initiative is followed in several areas worldwide (i.e. Italy www.reefcheckitalia.it, Philippines www.reefcheckphilippines.org, Malaysia www.reefcheck.org.my) aiming to stimulate local action towards tropical and temperate reef protection. In 2005 Reef Check California developed a specific volunteer monitoring program for California’s rocky reefs.

Reef Check Italia Onlus (www.reefcheckitalia.it), established in 2008, has developed a protocol for the monitoring of Mediterranean temperate reefs, the data collected by volunteers being stored in an online database (www.progettomac.it). ReefCheck Italia Onlus has contributed significantly in the organisation and development of protocols for the Coastal Environmental Monitoring (CEM) along Italian coasts, focusing its activity in Marine Protected Areas, mainly promoting the active participation of both recreational divers and students, who have the task to collect data underwater (Coastal Submerged Environment Monitoring, CSEM) and on the shoreline (Coastal Emerged Environment Monitoring, CEEM) respectively [84]. The database assembles information on selected endangered, invasive and keystone species and marine 
litter (on the beach and on sea bottom). To ensure data quality, a password is needed to upload information, which ensures that only trained volunteers contribute information. Quality control includes both automated processes and manual validation. ReefCheck Italia Onlus provided useful monitoring information on coastal biodiversity of Tavolara Punta Coda Cavallo MPA regarding the geographic, depth and abundance distribution of 14 species selected for the CSEM protocol for the Tyrrhenian Sea, and temperature profile data (recorded through dive computers and data logger devices) on a seasonal basis. Apart from the contribution to the monitoring of the MPA, ReefCheck Italia Onlus, boosted the knowledge and the direct perception on the effects of human activities and increased the awareness of local stakeholder groups, such as divers [84]. Currently ReefCheck is developing an app for smartphones in order to facilitate monitoring activities.

\subsection{Multidisciplinary cartographic platforms}

Recent studies have argued that advanced participatory platforms are the new generation of highly sophisticated tools that combine geospatial technology and Web 2.0 to reach a broad range of stakeholders with varied technical ability (or no technical expertise), so that they contribute their knowledge in an efficient and transparent way [55] (Ciobanu, Roche, Badard, \& Caron, 2007; Goodchild, 2007).

This advanced technology actually comprises cloud-based collaborative content systems for the mapping, processing and analysis of geospatial information. Therefore, these tools offer a lot more than just online visualizations of geographic information (Gould, 2008). Community-based portals may help people understand the 
real-world implications of different management regimes and environmental conditions and reveal trade-offs among possible management scenarios (Beck et al., 2009). Interactive web portals require simply an internet connection and a web browser in order to view and query geographic data using interactive maps and a toolbox for basic mapping functions (viewing, navigating, zooming and panning). Some of these tools provide personal space to administrators, or users, that enables data owners to upload and visualise their data, interact with the data and maps, or integrate multiple data layers to inform their designs. Additionally, data can be private or shared with other stakeholder groups, stimulating comments and/or consultation through forums. For most of these tools no prior technical expertise is required. Considering the complexity of the tools examined, most of them can incorporate powerful data analysis.

\subsubsection{Examples of advanced participatory platforms for resource management}

The common database on Mediterranean MPAs (MAPAMED, www.mapamed.org) developed by MedPAN and RAC/SPA aims to collect, organise and provide efficient, open accessed geospatial information and public documents. The inventory was first established in 2008, but was completely upgraded in 2012. Currently it provides information regarding geo-location for 677 MPAs covering about $7 \%$ of the total number of MPAs worldwide [87], habitats and species existing under special protection status, and their management and legislature documents. MAPAMED allows users to visualise the Mediterranean MPAs through a map interface and access referenced information, or search data through an advanced search. Information provided is based on the UNEP-WCMC (2010) data standards in order to facilitate sharing the protected areas data on an international scale. More detailed information 
was collected from MPA managers through online surveys, which may update directly information on their MPA, or validate existing information (Gabrié et al., 2012). The database has enabled the analysis and assessment of the status and trends of the Mediterranean network of MPAs according to international targets over the long term (Gabrié et al., 2012). MAPAMED database anticipates to become the region’s baseline and to supply international databases (Gabrié et al., 2012). Nevertheless, due to the portal's objective, MAPAMED provides limited interaction with the user.

Additionally, the World Database on Protected Areas (WDPA, www.wdpa.org) is a comprehensive global inventory of the world's protected areas created through a joint project of UNEP-WCMC and the IUCN World Commission on Protected Areas. A broad range of open accessed data is held within the WDPA for each site including information about designation and IUCN management category, historic changes in areas' boundaries, the annotation of habitat fields and administration. Critical information sources have been strengthened by the establishment of a consortium of international conservation organizations in 2002, which support the pooling of information from a broad range of resources and collaboration on the improvement of the structure of the WDPA, as well as the quality and quantity of the core data contained (Chape et al., 2005). The WDPA provides a unique tool to investigate progress in the development of the global network of protected areas, provides summary information at global, regional and national levels, while the GIS makes it possible to undertake spatial assessments, combining the protected areas information with other data layers, such as species or habitats and summarize the 'effectiveness' of the protected areas network. Since 2002, protected areas information from the WDPA has provided regular statistical and analytical information for the preparation 
of technical reports to the CBD Subsidiary Body on Scientific, Technical and Technological Advice (SBSTTA) (Mulongoy \& Chape 2004), thereby contributing to the key decisions on protected areas. Information provided by the portal is regularly updated (every 3-5 years) (Chape et al., 2005).

One of the most well-known examples that boosted the capacity of web platforms and cartographic design serving Marine Spatial Planning using the power of the web and GIS, is MarineMap. MarineMap (www.marinemap.org) responded to the call of California’s Marine Life Protection Act Initiative (MLPAI) for active public involvement in the planning processes of Marine Protected Areas in California [88; Fox et al., 2013]. MarineMap Oregon (www.oregon.marinemap.org) is a "mature” dynamic web portal and thus it provides a well-structured and informed Decision Support Tool for marine, terrestrial and atmospheric environments that has been used to inform decision-making (Beck et al, 2009; Merrifield et al., 2012). Map layers can be viewed and queried in reference to the three-dimensional Google Earth API which is a familiar, user-friendly and open source interface that provides cross-platform functionality. However, Google Earth API requires the download and installation of the Google Earth Plugin, which in many situations is not allowed to users. Information and metadata are well organised and linked to each other and therefore easily located by users with no technical expertise [55]. MarineMap was configured to support iterative sketching (“geodesign”) of different individual perspectives to map layers and inform marine spatial planning, and supported statistical analysis of data. It is adapted to be implementated on a global scale. MarineMap has evolved three times based on users' need to reach wide acceptance from the public and its total cost ranges from $\$ 250.000$ to $\$ 700.000$ per region [55]. 
SeaSketch (www.seasketch.org) is a next generation decision support tool for collaborative ocean planning for effective ocean planning for a range of end users, including government, industries, and regional institutions. SeaSketch was developed by the McClintock lab of the University of California, Santa Barbara (UCSB), Center for Marine Assessment and Planning to deliver a cutting-edge decision support tool and was released in November of 2012. SeaSketch in reality is a web-based ocean geodesign platform accessible via ArcGIS Online where users are able to initiate their own project by uploading map layers and defining "sketch classes". What is unique about SeaSketch is that the author can sketch on the different layers and share them with others to trigger discussions through an online map-based chat forum [89]. Regardless of technical or scientific ability, users of SeaSketch are able to easily view map data from authoritative sources from all over the world (e.g., distributions of human activities and resources). Using these maps as a reference, users are then able to sketch, save, and share management plans and discuss them with other users via a facilitated chat forum tied directly to their maps. SeaSketch is always adding to its current suite of spatial analytics, which in the future will include spatial dimensions of trade-offs in which users submit the spatial features of their plans to a biologicaleconomic model of trade-offs between ecosystem services in relation to potential management strategies (Wright, 2013). Unlike MarineMap, SeaSketch has an elaborate, interactive help system that allows users to ask questions, submit comments and vote for feature enhancements. SeaSketch has built in tools for designing and conducting surveys to gather new information about the distribution of resources and human activities in and around the ocean. Therefore, this data gathering capability SeaSketch provides is unique and worth mentioning feature. Consultation process along with sketches and comments can be extracted or included in a report. End-users 
may use easily the tool as a result of a fair amount of user testing with no or low experience in WebGIS. However, advanced analysis for environmental and socioeconomic assessments or future scenarios is possible but demands high-level programming expertise. Although SeaSketch was very recently established, it is a mature tool with demonstrated capabilities. It is a straightforward and user-friendly tool that supports interactive consultation and dialogue between stakeholders through an innovating approach.

In 2013 the Barbuda Council used SeaSketch to visualize and analyze geospatial information about the distribution of resources and human activities in Barbuda. The Council members using simple drawing tools authored draft maps indicating areas where any type of fishing is completely prohibited. Sketches were immediately evaluated to determine whether they met science and policy guidelines for ecosystem protection and minimizing impacts to fishermen on the island. The final outcome is a proposal of six sanctuaries in Barbuda. A public discussion forum in SeaSketch was used solicit feedback from the local stakeholders of Barbuda who had the opportunity to consult and use sketching tools to author modified versions of the council proposal and evaluate them using the reporting and analytical features in SeaSketch (SeaSketch News, 2013). Currently it is being applied also in the UK, US, Canada, New Zealand, the Mediterranean, the Galapagos, and Australia. SeaSketch has relatively low maintenance costs. The annual cost of SeaSketch is $\$ 10,100$ per year for the license and support fee. If hosting map services is required, the average cost is $\$ 5,000$ per year. Additionally the maintenance cost is $\$ 15,000$ / year (Will McClintock, pers. commun.). 


\section{Discussion}

Technological advances are increasing rapidly seeking to provide solutions to the changing demands of users (ㅁ1) and may provide a vehicle for reaching out to communities and institutions that hold crucial information capable of informing decisions and drawing new stakeholders into the MPA planning process [무]. However, successful attempts to include the public in a more communicative, interactive and organised way in MPA management worldwide are still limited [ㄷ4]. A successful participative tool corresponding to the high rate of needs and technological development should provide efficient information, comprehensively visualised by a range of stakeholders that are involved into a collaborative process through an interactive channel (Lu, 2011; Lin et al., 2013a). A generalised framework for the development of a successful community web-based tools is shown in Figure 1. In any participatory approach (Figure 1) the initial step is to define clearly the aims and the objectives to reach through the participatory process. Stakeholders through participation may contribute in the planning process by setting of priorities, objectives, purpose of spatial management plans, or even help to identify, group, and rank management problems, needs, and opportunities (Pomeroy \& Douvere, 2008). During the evaluation phase stakeholders may be involved in selecting of plan options (Pomeroy \& Douvere, 2008). Even after the implementation of management plans, adaptive management requires consultation about the overall effectiveness in achieving goals and objectives and exploration of alternative plans (McClintock, 2013). Identification, characterisation and prioritisation of the stakeholders is necessary in order to recognize the key actors who have a vested interest in the focus area, the ones who are weaker and need to be heard, or may already have a voice in 
determining and assessing management strategies, and the ones who may participate in the process in a future step (Grimble and Wellard, 1997; Mushove and Vogel, 2005- Prell 2009).

Any participation strategy should aim for maximum participation through a broad community of practice to involve all relevant stakeholders early and continually in all phases of the planning, plan evaluation, implementation and post-implementation management phases, and not just consulted afterwards (Shepherd, 2004; Gleason et al, 2010; McCall \& Dunn, 2012). Early and consistent engagement of stakeholders will help to break down conflicts, facilitate trust and information-sharing, and allow for a broad understanding and vision of the region being managed (Reed, 2008). However in practice not all people and/or organizations that have a stake in how the ecosystem is being managed is necessary to be actively involved in every stage of the decision making process, but in some cases they may simply be informed (Agardy et al., 2011UNEP).

Web-based tools for communication are increasing in popularity since they are addressed to reach a much wider audience and support the collection of new information (McClintock, 2013) and support open software tools available to public. Providing accurate and efficient information on the distribution of resources and human activities in the MPA area, for the development and evaluation of spatial management strategy is the building block of an inclusive and transparent planning process [92] (McClintock, 2013).

Social media have been used effectively to generate the gathering of new information regarding MPA management through targeted interviews and surveys reaching a wide audience (Wright, 2013). A powerful characteristic however of the social web is its 
capacity to reach a broader target audience and to distribute information in various forms corresponding to the preferences of each target group rapidly through news feeds and notifications and mobile technology (Kopke et al. [75]. Moreover, if we consider that actors are the nodes in social networks who are tied to one another through socially meaningful relations and share information (De Longueville, 2010; Prell et al., 2008), tools like Social media may provide useful information regarding stakeholders networks and their features, in order to identify key stakeholders, their roles and power, or measure components such as "homophily” and "centrality” for further analysis (e.g. Social Network Analysis; Prell et al., 2008). Several authors have highlighted the future potential of Social media in resource management as systems for collecting huge amount of information that is indexed, classified and commented upon collectively through "liking” buttons, shared bookmarks, pop-up windows and comment features associated with specific layers, maps or thematic content for immediate feedback (Kopke et al. [75]). Collaborative “tagging” or “rating” could potentially provide an estimate of the information quality (De Longueville, 2010). However these approaches have not been applied yet, and need to be monitored carefully in order to provide reliable information in the development of the participation process [75].

Other examples of web tools that have been used to support the collection of new information for MPA management needs are crowdsourcing and citizen science (Wright, 2013). Many governments and non-government agencies (NGOs) create monitoring programs based on citizen science in provide useful information and help the MPA reach its management objectives in times of resource and budgetary constraints $[74,75]$. Even though crowdsourcing datasets raise a series of questions in relation to their quality due to the non-expertise of volunteers [69, 81-83], it has been 
proved that when appropriate training, standardised protocols and forms are provided information could be scientifically sound $[78,84]$. Collective intelligence offers a good alternative for retrieval, ordering and quality control for pertinent information, particularly for a huge and constantly growing mass of user-generated information (De Longueville, 2010). From this perspective, tools like these advance in time, cost and data accuracy since their capacity allows the simultaneous collection of multiple measurements on a single click (i.e. obtaining coordinates, pictures, measures, storage and organization of information collected). Therefore, citizen science may provide an excellent support for long-term monitoring of key species in MPA management, environmental awareness and involvement of public in general.

Interactive geospatial portals have an added-value as they integrate geographical dimensions and ecological and socio-economic information holistically (De Longueville, 2010) and have integrated high level of interaction required to efficiently support collaborative and participative processes in MPA management (Jankowski and Nyerges, 2001). Interactive community based web tools have helped MPA managers to engage stakeholders into a multi-disciplinary way, perform future scenarios and find optimal answers together through collaborative modes, such as by joining a virtual group through the Internet (Hara et al., 2003; Beck et al., 2009). These highly sophisticated web tools have used an intuitive user experience to simplify complicated spatial concepts and deliver openly critical information immediately through sufficiently interactive and attractive interfaces. Additionally, collaborative geodesign is the most reasonable solution to support information collection, collaborative experimentation, and decision-making, particularly when non-expert participants are involved in MPA management (Jankowski and Nyerges, 2001; Balram and Dragicevic, 2006; Elwood, 2006; McHugh et al., 2009)- Lin et al., 
2013b), and therefore reliance on GIS technicians (McClintock, 2013).

Different types of information need to be translated so it can be easily understood by people [99].Visualization of information through maps is one of the basic advantages of geographic information tools (Longley et al., 2011). According to Churchill et al. (2001) and Abel et al. (2005), optimised visualisation of information is the best method for knowledge sharing and development of mutual understanding on the ecosystem processes between stakeholders with different backgrounds (Lin et al., 2013). Currently, traditional spatial analysis and visualization in 2D cannot meet the advanced needs of MPA management, particularly when solving problems related to complex spaces (Lin et al., 2013b). Providing multi-dimensional visualisation enables the presentation of geographic scenarios and phenomena to be more dynamic may create stakeholders a better understanding in complicated spatial issues [6] and thus, would enable them to consult or examine alternatives simultaneously by using common information spaces (Lin et al., 2013).

Discussions regarding the future web in a data-based form where any piece of knowledge will have a computer-understandable structure and content, so that the retrieval, discovery and combination of information will be a lot easier and more powerful for the end user are increasing (Berners-Lee and Fischetti , 1999, [95,59]). Utilizing the Semantic Web to support building knowledge and semantics into the next generation of scientific tools will support smart processing of geospatial metadata, data, information, knowledge, and services for virtual communities and multiple scientific domains (Hendler, 2003). The geospatial Semantic Web is a Web in which the browser, crawler, and other tools understand spatial content and can exploit this knowledge on-the-fly (Maué \& Schade, 2009). Enabling technologies that 
provide technological support functions, such as collecting data through observations and utilizing knowledge through a semantic web (Yang et al., 2010) are essential ingredient to cross-domain collaborations, interdisciplinary discoveries (Berners-Lee, Hendler, \& Lassila, 2001; Brodaric et al., 2009).

Technology may provide a vehicle for reaching out communities and institutions that hold crucial information capable of informing decisions and drawing new stakeholders into the MPA planning process [이. Tools we have in our hands today provide adequate technical solutions through the support and cooperation between the involved parties and the resulting input of knowledge (Luyet et al., 2012). However, it must be stressed that simply copying the best examples of participation will not guarantee success in other case studies (Luyet et al., 2012). Nor that a successful stakeholder participation guarantees that the process will reach successfully its targets (Luyet et al., 2012). Stakeholder participation alone is not enough. Social change occurs as people learn from each other through their social networks (Prell et al., 2008), but also through approaches like environmental education and capacity development are needed to guarantee behaviour and attitude changes so that the management processes can be sustainable over time $[15,100]$. Face to personal communication and face-to-face informal conversations for true dialogue and negotiaton is still crucial in real world cases of governance and decision making (Markantonatou et al., 2013).

\section{Acknowledgements}

This research was funded by the European project "Training Network for Monitoring Mediterranean Marine Protected Areas” (MMMPA: FP7-PEOPLE-2011-ITN, Grant Agreement no.: 290056). 


\section{References}

[1] B.S. Halpern, S. Walbridge, K.A. Selkoe, C.V. Kappel, F. Micheli, C. D'Agrosa, J.F. Bruno, K.S. Casey, C. Ebert, H.E. Fox, R. Fujita, D. Heinemann, H.S. Lenihan, E.M.P. Madin, M.T. Perry, E.R. Selig, M. Spalding, R. Steneck, and R. Watson, A global map of human impact on marine ecosystems, Science 319 (2008), pp. 948-952.

[2] T. Agardy, G. Notarbartolo di Sciara, and P. Christie, Mind the gap: Addressing the shortcomings of marine protected areas through large scale marine spatial planning, Marine Policy 35 (2011), pp. 226-232.

[3] C. Ojeda-Martinez, F. Gimenez Casalduero, J.T. Bayle-Sempere, C. Barbera Cebrian, C. Valle, J. Luis Sanchez-Lizaso, A. Forcada, P. Sanchez-Jerez, P. Martin-Sosa, J.M. Falcon, F. Salas, M. Graziano, R. Chemello, B. Stobart, P. Cartagena, A. Perez-Ruzafa, F. Vandeperre, E. Rochel, S. Planes, and A. Brito, A conceptual framework for the integral management of marine protected areas, Ocean \& Coastal Management 52 (2009), pp. 89-101.

[4] A.S. Marques, T.B. Ramos, S. Caeiro, and M.H. Costa, Adaptive-participative sustainability indicators in marine protected areas: Design and communication, Ocean \& Coastal Management 72 (2013), pp. 36-45.

[5] R.E. Freeman, Strategic Management: a Stakeholder Approach, Pitman, Boston, 1984.

[6] R. Kay, S. Gardner, J. Bello Pineda, K. Juntarashote, G. Pierce, C. Pita, J. Wang, and R. Chuenpagdee, Concepts and Tools for ICZM with a Special Focus on Stakeholder Engagement Visualisation Tools in Fisheries Management, INCOFISH Report, Work Package 6, Deliverable 6.1 (2006),p. 35.

[7] J.M. Bryson, M.Q. Patton, and R.A. Bowman, Working with evaluation stakeholders: A rationale, step-wise approach and toolkit, Evaluation and Program Planning 34 (2011), pp. 1-12.

[8] B. Cicin-Sain, and R.W. Knecht, Integrated coastal and ocean management: Concepts and practices, Island Press, California, 1998.

[9] M.S. Reed, Stakeholder participation for environmental management: A literature review, Biological Conservation 141 (2008), pp. 2417-2431. 
[10] R.A. Matthew, O. Brown, and D. Jensen, From Conflict to Peacebuilding: The Role of Natural Resources and the Environment, United Nations Environment Programme (UNEP), Geneva, 2009.

[11] D.N. Brown, and R.S. Pomeroy, Co-management of caribbean community (CARICOM) fisheries, Marine Policy 23 (1999), pp. 549-570.

[12] F. Berkes, R. Mahon, P. McConney, P. R., and R. Pomeroy, Berkes, F., R. Mahon, P. McConney, R. Pollnac and R. Pomeroy. 2001. Managing smallscale fisheries: alternative directions and methods, IDRC Books, Canada, 2001.

[13] R.S. Pomeroy, Devolution and Fisheries Co-management. , in Collective Action, Property Rights and Devolution of Natural Resource Management Exchange of Knowledge and Implications for Policy, R. Meinzen-Dick, A. Knox and M. Di Gregorio (eds.), Zentralstelle fur Ernahrung und Landwirtschaft, Feldafing, Germany, 2001.

[14] M. Bouamrame, Biodiversity and stakeholders: concertation itineraries, Biosphere reserves, Technical Notes 1, UNESCO, Paris, 2006.

[15] R. Pomeroy, and F. Douvere, The engagement of stakeholders in the marine spatial planning process, Marine Policy 32 (2008), pp. 816-822.

[16] R. Bouwen, and T. Taillieu, Multi-party collaboration as social learning for interdependence: Developing relational knowing for sustainable natural resource management, Journal of Community \& Applied Social Psychology 14 (2004), pp. 137-153.

[17] T. Gray, and J. Hatchard, A complicated relationship: Stakeholder participation and the ecosystem-based approach to fisheries management, Marine Policy 32 (2008), pp. 158-168.

[18] S.D. Brody, Measuring the effects of stakeholder participation on the quality of local plans based on the principles of collaborative ecosystem management, Journal of Planning Education and Research 22 (2003), pp. 407-419.

[19] J. Pretty, and D. Smith, Social capital in biodiversity conservation and management, Conservation Biology 18 (2004), pp. 631-638.

[20] S. Gelcich, G. Edwards-Jones, and M.J. Kaiser, Importance of attitudinal differences among artisanal fishers toward co-management and conservation of marine resources, Conservation Biology 19 (2005), pp. 865-875. 
[21] J.T. du Toit, B.H. Walker, and B.M. Campbell, Conserving tropical nature: current challenges for ecologists, Trends in Ecology \& Evolution 19 (2004), pp. 12-17.

[22] A. Van Den Brink, R. Van Lammeren, R. Van De Velde, and S. Dane, Imaging the Future: Geo-visualisation for Participatory Spatial Planning in Europe. Imaging the future, Mansholt Publication Series, Wageningen Academic Publishers, 2007.

[23] H. Locke, and P. Dearden, Rethinking protected area categories and the new paradigm, Environmental Conservation 32 (2005), pp. 1-10.

[24] J. Areizaga, M. Sano, R. Medina, and J. Juanes, Improving public engagement in ICZM: A practical approach, Journal of Environmental Management 109 (2012), pp. 123-135.

[25] K. Sayce, C. Shuman, D. Connor, A. Reisewitz, E. Pope, M. Miller-Henson, E. Poncelet, D. Monie, and B. Owens, Beyond traditional stakeholder engagement: Public participation roles in California's statewide marine protected area planning process, Ocean \& Coastal Management 74 (2013), pp. 57-66.

[26] R. Varjopuro, T. Gray, J. Hatchard, F. Rauschmayer, and H. Wittmer, Introduction: Interaction between environment and fisheries - The role of stakeholder participation, Marine Policy 32 (2008), pp. 147-157.

[27] M. Gauthier, L. Simard, and J.-P. Waaub, Public participation in strategic environmental assessment (SEA): Critical review and the Quebec (Canada) approach, Environmental Impact Assessment Review 31 (2011), pp. 48-60.

[28] E. Fox, E. Poncelet, D. Connor, J. Vasques, J. Ugoretz, S. McCreary, D. Monie, M. Harty, and M. Gleason, Adapting stakeholder processes to regionspecific challenges in marine protected area network planning, Ocean \& Coastal Management 74 (2013), pp. 24-33.

[29] C. Ehler, and F. Douvere, Marine Spatial Planning: a step-by-step approach toward ecosystem-based management, UNESCO, Paris, 2009.

[30] M.K. McCall, and C.E. Dunn, Geo-information tools for participatory spatial planning: Fulfilling the criteria for 'good' governance?, Geoforum 43 (2012), pp. 81-94.

[31] M. Helvey, Seeking consensus on designing marine protected areas: Keeping the fishing community engaged, Coastal Management 32 (2004), pp. 173-190. 
[32] B. Cicin-Sain, and S. Belfiore, Linking marine protected areas to integrated coastal and ocean management: A review of theory and practice, Ocean \& Coastal Management 48 (2005), pp. 847-868.

[33] N.E. Stump, and L.K. Kriwoken, Tasmanian marine protected areas: Attitudes and perceptions of wild capture fishers, Ocean \& Coastal Management 49 (2006), pp. 298-307.

[34] L.C. Stringer, A.J. Dougill, E. Fraser, K. Hubacek, C. Prell, and M.S. Reed, Unpacking "participation" in the adaptive management of social ecological systems: A critical review, Ecology and Society 11 (2006), p. 39.

[35] C. Sudtongkong, and E.L. Webb, Outcomes of State-vs. Community-Based Mangrove Management in Southern Thailand, Ecology and Society 13 (2008), p. 27.

[36] C. Prell, K. Hubacek, and M. Reed, Stakeholder Analysis and Social Network Analysis in Natural Resource Management, Society \& Natural Resources 22 (2009), pp. 501-518.

[37] J.E. Innes, and D.E. Booher, Reframing public participation: strategies for the 21st century, Planning Theory \& Practice 5 (2004), pp. 419-436.

[38] J.B. Davis, What Are the Main Challenges Facing the MPA World?, MPA News, International News and Analysis on Marine Protected Areas 12 (2011), pp. 3-4.

[39] S. Miller-Taei, and W. Kostka, Paying for MPAs: Examples of Large-Scale Fundraising for Planning and Management MPA News, International News and Analysis on Marine Protected Areas 13 (2012), pp. 1-4.

[40] R.S. Pomeroy, L.M. Watson, J.E. Parks, and G.A. Cid, How is your MPA doing? A methodology for evaluating the management effectiveness of marine protected areas, Ocean and Coastal Management 48 (2005), pp. 485-502.

[41] D.H. Walker, Decision support, learning and rural resource management, Agricultural Systems 73 (2002), pp. 113-127.

[42] S.M. Garcia, Potential contribution of the Internet to a global community of practice for fishery management, ICES Journal of Marine Science 68 (2011), pp. 1800-1804.

[43] S. Claus, B. Vanhoorne, E. Vanden-Berghe, and J. Mees, Development of the ENCORA portal: an internet based facility supporting Euwide contact search for ICZM related science, practice, and policy communities, in VLIZ Young 
Scientists’ Day, VLIZ Special Publication, Mees J. and J. Seys eds., Brugge, 2007, pp. 55.

[44] M. Mossbauer, G. Schernewski, and S. Bock, The effectiveness of coastal management web portals - a critical analysis, Journal of Coastal Conservation 16 (2012), pp. 439-448.

[45] A.J. Meijer, Publishing public performance results on the Internet - Do stakeholders use the Internet to hold Dutch public service organizations to account?, Government Information Quarterly 24 (2007), pp. 165-185.

[46] Internet World Stats (I.W.S.), www.internetworldstats.com, 2012.

[47] A.J. Meijer, Transparent government: Parliamentary and legal accountability in an information age, Information Polity 8 (2003), pp. 67-78.

[48] W. Wong, and E. Welch, Does E-government promote accountability? A comparative analysis of Web site openness and government accountability, Governance 17 (2004), pp. 275-297.

[49] D.M. Aanensen, D.M. Huntley, E.J. Feil, F. al-Own, and B.G. Spratt, EpiCollect: Linking Smartphones to Web Applications for Epidemiology, Ecology and Community Data Collection, Plos One 4 (2009), e6968, doi:10.1371/journal.pone.0006968.

[50] J.L. Dickinson, J. Shirk, D. Bonter, R. Bonney, R.L. Crain, J. Martin, T. Phillips, and K. Purcell, The current state of citizen science as a tool for ecological research and public engagement, Frontiers in Ecology and the Environment 10 (2012), pp. 291-297.

[51] P. Meier, New information technologies and their impact on the humanitarian sector, International Review of the Red Cross 93 (2011), pp. 1239-1263.

[52] Canalys, www.canalys.com/newsroom/mobile-device-market-reach-26-billionunits-2016, 2013.

[53] B. De Longueville, The next generation? Concepts and methods for the geospatial Web 2.0, Computers, Environment and Urban Systems 34 (2010), pp. 299-308.

[54] G. Bugs, C. Granell, O. Fonts, J. Huerta, and M. Painho, An assessment of Public Participation GIS and Web 2.0 technologies in urban planning practice in Canela, Brazil, Cities 27 (2010), pp. 172-181. 
[55] M.S. Merrifield, W. McClintock, C. Burt, E. Fox, P. Serpa, C. Steinback, and M. Gleason, MarineMap: A web-based platform for collaborative marine protected area planning, Ocean \& Coastal Management 74 (2012), pp. 67-76.

[56] B. Viswanath, A. Mislove, M. Cha, and K.P. Gummadi, On the evolution of user interaction in Facebook, in Proceedings of the 2nd ACM Workshop on Online social networks (WOSN '09). ACM, New York USA (2009), 37-42pp.

[57] A. Acquisti, and R. Gross, Imagined Communities: Awareness, Information Sharing, and Privacy on the Facebook, in Privacy Enhancing Technologies, (2006), pp. 36-58.

[58] C.L. Catlin-Groves, The Citizen Science Landscape: From Volunteers to Citizen Sensors and Beyond, International Journal of Zoology Article ID 349630 (2012), p. 14.

[59] S. Stieglitz, and L. Dang-Xuan, Social media and political communication: a social media analytics framework., Social Network Analysis and Mining (2012), doi:10.1007/s13278-012-0079-3.

[60] D. Gurteen, Leading Issues in Social Knowledge Management., Vol. 1, Academic Conferences Limited, United Kingdom, 2012.

[61] P.A. Longley, M.F. Goodchild, D.J. Maguire, and D.W. Rhind, Geographic Information Systems and Science, John Wiley \& Sons Inc, 2001.

[62] S. Geertman, Participatory planning and GIS: a PSS to bridge the gap, Environment and Planning B-Planning \& Design 29 (2002), pp. 21-35.

[63] V. Valavanis, Geographic Information Systems in Oceanography and Fisheries, Taylor \& Francis, London, 2002, p. 240.

[64] Nature editorial, Think global. 'Virtual globe' software is transforming our ability to visualise and hypothesize in three dimensions, Nature 439 (7078) (2006).

[65] F. Koti, and D. Weiner, (Re)Defining peri-urban residential space using participatory GIS in Kenya, The Electronic Journal on Information Systems in Developing Countries 25 (2006), pp. 1-12.

[66] G. Rambaldi, R. Chambers, M. McCall, and J. Fox, Practical ethics for PGIS practitioners, facilitators, technology intermediaries and researchers, Participatory Learning and Action 54 (2006), pp. 106-133. 
[67] N.J. Obermeyer, The evolution of Public Participation GIS, Cartography and Geographic Information Systems 25 (1998), pp. 65-66.

[68] P.A.K. Kyem, and J.C. Saku, Web-based GIS and the future of Participatory GIS applications within local and indigenous communities, EJISDC 38 (2009), pp. 1-16.

[69] M. Goodchild, Citizens as voluntary sensors: spatial data infrastructure in the world of Web 2.0, International Journal of Spatial Data Infrastructures Research 2 (2007), pp. 24-32.

[70] F. Danielsen, N.D. Burgess, A. Balmford, P.F. Donald, M. Funder, J.P.G. Jones, P. Alviola, D.S. Balete, T. Blomley, J. Brashares, B. Child, M. Enghoff, J. Fjeldsa, S. Holt, H. Hubertz, A.E. Jensen, P.M. Jensen, J. Massao, M.M. Mendoza, Y. Ngaga, M.K. Poulsen, R. Rueda, M. Sam, T. Skielboe, G. StuartHill, E. Topp-Jorgensen, and D. Yonten, Local Participation in Natural Resource Monitoring: a Characterization of Approaches, Conservation Biology 23 (2009), pp. 31-42.

[71] P.J. Agerfalk, and B. Fitzgerald, Outsourcing to an unknown workforce: Exploring opensourcing as a global sourcing strategy, MIS Quarterly 32 (2008), pp. 385-409.

[72] R.S. Koss, K. Miller, G. Wescott, A. Bellgrove, A. Boxshall, J. McBurnie, A. Brunce, P. Gilmour, and D. Ierodiaconou, An evaluation of Sea Search as a citizen science programme in Marine Protected Areas, Pacific Conservation Biology 15 (2009), pp. 116-127.

[73] R.S. Koss, and J.Y. Kingsley, Volunteer health and emotional wellbeing in marine protected areas, Ocean \& Coastal Management 53 (2010), pp. 447453.

[74] D.M. Whitaker, The use of full-time volunteers and interns by naturalresource professionals, Conservation Biology 17 (2003), pp. 330-333.

[75] K. Kopke, N. Dwyer, K. Belpaeme, M. Berman, K. Taylor, D. Hart, and D. Wright, Improving Participation of Users in Coastal Web Atlases, Littoral 201012001 (2011), pp. 8, doi:http://dx.doi.org/10.1051/litt/201112001

[76] A. Irwin, S. Georg, and P. Vergragt, The social management of environmental change, Futures 26 (1994), pp. 323-334. 
[77] W.R.T. Darwall, and N.K. Dulvy, An evaluation of the suitability of nonspecialist volunteer researchers for coral reef fish surveys. Mafia Island, Tanzania - A case study, Biological Conservation 78 (1996), pp. 223-231.

[78] C. Cerrano, C.G. Di Camillo, M. Milanese, M. Previati, G. Rossi, A. Scinto, E. Turicchia, and M. Ponti, Education through participation: the role of citizen science in marine habitat conservation, PIXEL New perspectives in science education, 8-9 March, Florence, Italy, 2012.

[79] J. Foster-Smith, and S.M. Evans, The value of marine ecological data collected by volunteers, Biological Conservation 113 (2003), pp. 199-213.

[80] G. Wescott, The long and winding road: The development of a comprehensive, adequate and representative system of highly protected marine protected areas in Victoria, Australia, Ocean \& Coastal Management 49 (2006), pp. 905-922.

[81] M. Scales, Training and experience in community based monitoring: valueadding for MPA management. Honours Thesis, Deakin University, 2006.

[82] M.F. Goodchild, Citizens as sensors: the world of volunteered geography, GeoJournal 69 (2007), pp. 211-221.

[83] A. Flanagin, and M. Metzger, The credibility of volunteered geographic information, GeoJournal 72 (2008), pp. 137-148.

[84] C. Cerrano, A. Navone, M. Ponti, F. Betti, G. Nervegna, M. Palma, U. Pantaleo, G. Pitzianti, M. Previati, G. Rossi, A. Scinto, and G. Spano, Environmental volunteerism in MPAs: the experience at Tavolara Punta Coda Cavallo (Sardinia, Italy). Studi Trent. Sci. Nat. 89 (2011), pp. 63-68.

[85] D. Wright, N. Dwyer, K. Kopke, and L. O’Dea, Report of International Coastal Atlas Network Workshop 4: Formalizing the Network, Engaging the Mediterranean, Trieste, Italy, 2010.

[86] K. Belpaeme, and H. Maelfait, Belgium, in Coastal Informatics: Web Atlas Design and Implementation, D. Wright, E. Dwyer and V. Cummins eds., Information Science Reference, IGI Global, 2010, pp. 156-164.

[87] C. Gabrié, E. Lagabrielle, C. Bissery, E. Crochelet, B. Meola, C. Webster, J. Claudet, A. Chassanite, S. Marinesque, P. Robert, M. Goutx, and C. Quod, The Status of Marine Protected Areas in the Mediterranean Sea., MedPAN \& CAR/ASP, 2012. 
[88] M.M. Foley, B.S. Halpern, F. Micheli, M.H. Armsby, M.R. Caldwell, C.M. Crain, E. Prahler, N. Rohr, D. Sivas, M.W. Beck, M.H. Carr, L.B. Crowder, J.E. Duffy, S.D. Hacker, K.L. McLeod, S.R. Palumbi, C.H. Peterson, H.M. Regan, M.H. Ruckelshaus, P.A. Sandifer, and R.S. Steneck, Guiding ecological principles for marine spatial planning, Marine Policy 34 (2010), pp. 955-966.

[89] Marine Science Institute, SeaSketch, http://mcclintock.msi.ucsb.edu/projects/seasketch, 2013.

[90] Secretariat of the Convention on Biological Diversity and the Scientific and Technical Advisory Panel- GEF, Marine Spatial Planning in the Context of the Convention on Biological Diversity: A study carried out in response to CBD COP 10 decision X/29, Technical Series No. 68, Montreal, 2012, pp. 44.

[91] L.J. Carton, and W.A.H. Thissen, Emerging conflict in collaborative mapping: Towards a deeper understanding?, Journal of Environmental Management 90 (2009), pp. 1991-2001.

[92] V. Stelzenmüller, J. Lee, A. South, J. Foden, and S.I. Rogers, Practical tools to support marine spatial planning: A review and some prototype tools, Marine Policy 38 (2013), pp. 214-227.

[93] J. Doody, Information required for integrated coastal zone management: conclusions from the European Demonstration Programme, Coastal Management 31, (2003), pp. 163-173.

[94] I. Geskou, Developing the vision: managing the coastal zone of magnesia through information and consent, Coastal Management 31 (2003), pp. 187194.

[95] R. Thamm, S. Bock, and G. Schernewski, TRegional Information Systems and Coastal Databases for ICZM in Germany - are they efficient and informative?, in Coastal development: The Oder estuary and beyond Coastline Reports, G. Schernewski, Glaeser, Scheibe, Sekścińska and R. Thamm eds., Coastal development: The Oder estuary and beyond Coastline Reports 8: 151161

[96] E.C. Carballo-Cardenas, A.P.J. Mol, and H. Tobi, Information systems for marine protected areas: How do users interpret desirable data attributes?, Environmental Modelling \& Software 41 (2013), pp. 185-198. 
[97] M.B. Mascia, The human dimension of coral reef marine protected areas: Recent social science research and its policy implications, Conservation Biology 17 (2003), pp. 630-632.

[98] E. Jensen, Evaluate impact of communication, Nature 469 (2011), pp. 162162.

[99] A. Pickaver, R. Steijn, M. Ferreira, P. Czerniak, and E. Devilee, Integrated Coastal Zone Management. Participation practices in Europe, European Union, 2010.

[100] G. Di Carlo, A. Lopez, and F. Staub, Capacity building strategy to enhance the management of MPAs in the Mediterranean Sea, 2012.

[101] L. O’Dea, V. Cummins, D. Wright, N. Dwyer, and I. Ameztoy, Report on Coastal Mapping and Informatics Trans-Atlantic Workshop 1: Potentials and Limitations of Coastal Web Atlases, Coastal \& Marine Resources Centre, Ireland, 2007. 
Table 1: Different levels of public participation (adapted from Bouamrame, 2006), their respected objectives (adapted from Douvere \& Pomeroy, 2008), benefits of each approach (adapted by Bouwen \& Taillieu, 2005) and traditional approaches (adapted from Areizaga et al., 2012) that have been commonly used in resource management.

\begin{tabular}{|c|c|c|c|c|}
\hline $\begin{array}{c}\text { Level of } \\
\text { Participation }\end{array}$ & Definition & Objective & $\begin{array}{c}\text { Advantage from } \\
\text { Participation Process }\end{array}$ & $\begin{array}{c}\text { Traditional tools (formal } \\
\text { \& informal) }\end{array}$ \\
\hline Communication & $\begin{array}{l}\text { Authorities responsible for MSP want to convey a message to a } \\
\text { target audience and obtain approval for what their message asserts, } \\
\text { suggests, and decides. Communication does not involve the } \\
\text { stakeholders in any active way }\end{array}$ & $\begin{array}{l}\text { Descending univocal } \\
\text { flows }\end{array}$ & $\begin{array}{l}\text { Information exchange } \\
\text { provides the cognitive }\end{array}$ & $\begin{array}{l}\text { Official bulletins, } \\
\text { publications, mailing, }\end{array}$ \\
\hline Information & $\begin{array}{l}\text { Authorities responsible for MSP want to keep a target audience } \\
\text { informed about their intentions, decisions and attempts to provide a } \\
\text { basis of understanding; but don't expect any particular reaction. } \\
\text { Unlike communication, the information is intended to be objective } \\
\text { and represents a method of empowering stakeholders to react to } \\
\text { decisions or take a position with full knowledge of the facts }\end{array}$ & $\begin{array}{l}\text { Descending univocal } \\
\text { flows }\end{array}$ & $\begin{array}{l}\text { basis for enhancing the } \\
\text { interchange between } \\
\text { expert and experiential } \\
\text { knowledge. }\end{array}$ & $\begin{array}{l}\text { expositions, information } \\
\text { numbers, web pages, } \\
\text { announcements, personal } \\
\text { meetings, phone calls }\end{array}$ \\
\hline Consultation & $\begin{array}{l}\text { Authorities responsible for MSP collect the opinions of } \\
\text { stakeholders you have consulted with no guarantee that the } \\
\text { opinions expressed will be taken into account }\end{array}$ & Reciprocal flows & $\begin{array}{l}\text { Provides the opportunity } \\
\text { for organisational } \\
\text { members to use valued } \\
\text { skills and abilities }\end{array}$ & \\
\hline Dialogue & $\begin{array}{l}\text { A form of 'horizontal' interaction among stakeholders who are } \\
\text { positioned as equals. There is no precise purpose other than to } \\
\text { know and understand one another better. Dialogue is intended to } \\
\text { create a sense of proximity and mutual understanding about the } \\
\text { problems and solutions for a particular MSP area }\end{array}$ & Develop proximity & $\begin{array}{l}\text { towards important goals, } \\
\text { to gain self-confidence } \\
\text { and to engage in co- } \\
\text { ownership of projects. It } \\
\text { is the result of synthesis } \\
\text { of information gained } \\
\text { through participatory } \\
\text { process. }\end{array}$ & $\begin{array}{l}\text { Commissions, multilateral } \\
\text { meetings, frameworks for } \\
\text { agreement, phone calls, } \\
\text { meetings }\end{array}$ \\
\hline
\end{tabular}


A form of 'horizontal' interaction among stakeholders who are

positioned as equals. Unlike dialogue, the purpose is to develop a

common position among a group of stakeholders that can be

presented or defended before the authorities responsible for MSP.

A form of 'horizontal' interaction in which both stakeholders and

Negotiation

the authorities responsible for MSP have equal powers for decision- Reach a decision

making
Bringing together

stakeholders of diverse

Determine objectives and

actions

policy, NGOs, private

sector, conservation,

marine recreation) to

achieve representation

on a specific issue to

forums, surveys, interviews,

commissions, working

identify MPA objectives

and process a set of

management strategies. 
Figure 2: Generalised framework for developing a community web tool for enhancing participation and empowerment in MPA management. 
1. Identify stakeholders, characteristics, preferen

2. Identify participation level and time

1. Define clear targets of the project

2. Build conceptual framework that relates the ecosystem components and human
activities relevant to the issues under study Understanding of the ecosystem components Identify information needed

3. Collect information

Different information formats
(photos maps, videos, spatial data

(photos, maps, videos, spatial data)
Identification of data gaps

4. Develop a geospatial web tool

Organisation, Homogenisation, Classification of

Integration of different forms
Web semantics

5. Analyse information

(modeling, assessments, future scenarios

Results

Transformation of results in different formats

Dissemination and Visualisation of out put
Set priorities, objectives and purpose of spatial management

Identify, group, and rank management problems, needs, and opportunities

Preferences on the methods, formats and tools
Analysis of existing and alternative plans

3. Select Participation tools and methods

INFORMATION,

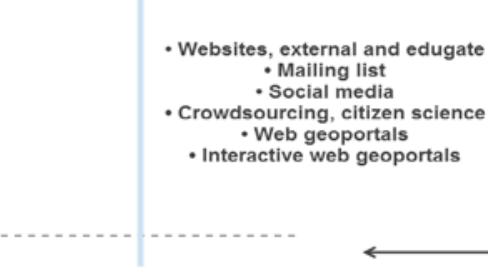

CONSULTATION

- Mailing list

- Social media
- Interactive web geoportals

Collection of new information

Validation of information
(scientific information and local knowledge, perceptions)

- Interactive web

\section{gertive we}

NEGOTIATION 
